\title{
INVENTÁRIO DOS BENS CULTURAIS RELATIVOS AO PLANO DE AÇÃO DO GOVERNO CARVALHO PINTO (1959-1963).
}

MÔNICA JUNQUEIRA DE CAMARGO, UNIVERSIDADE DE SÃO PAULO, SÃO PAULO, SÃO PAULO, BRASIL Arquiteta, doutora em História da Arquitetura e livre-docente pela Universidade de São Paulo. Docente da Faculdade de Arquitetura e Urbanismo da Universidade de São Paulo, onde desenvolve a linha de pesquisa Arquitetura e Cidade Moderna e Contemporânea, particularmente arquitetura brasileira e patrimônio histórico. Diretora do Centro de Preservação Cultural da USP (2014-atual).E-mail: junqueira.monica@usp.br DOI

http://dx.doi.org/10.11606/issn.1980-4466.v0iesp21p164-203 


\section{INVENTÁRIO DOS BENS CULTURAIS RELATIVOS AO PLANO DE AÇÃO DO GOVERNO CARVALHO PINTO (1959-1963). \\ MÔNICA JUNQUEIRA DE CAMARGO}

\section{RESUMO}

O inventário desta documentação revela as diretrizes e ações de um importante Plano de Governo nunca antes perscrutado. O Plano de Ação do Governo Carvalho Pinto (1959-1963) - PAGE, como era conhecido - teve por objetivo a criação de uma tecnocracia democrática para racionalizar o serviço público e promover o desenvolvimento do Estado de São Paulo, cujos investimentos foram estruturados em três setores: 1- melhoria das condições do Homem, que incluía as áreas de educação, cultura e pesquisa; justiça e segurança; saúde pública e assistência social, e sistemas de água e esgoto; 2- infraestrutura, abrangendo energia; ferrovias; rodovias; pontes municipais; aeroportos, portos e navegação; e 3- expansão agrícola. Esses investimentos resultaram em mais de mil projetos, envolvendo cerca de 160 arquitetos, que nunca foram estudados no seu conjunto. Não mais que uma dezena é conhecida pela notoriedade de seus autores e ainda assim quase nunca relacionada ao PAGE. Dispersas em centenas de municípios do estado de São Paulo, essas obras têm sua documentação também espalhada por diversos arquivos públicos: IPESP; FECE; CPOS; SEF-USP; secretarias da Agricultura e da Saúde, além dos arquivos dos próprios arquitetos. Periódicos especializados, a grande imprensa e os depoimentos dos vários envolvidos têm revelado aspectos desconhecidos e importantes para a restituição do processo. O inventário, que vem sendo realizado sob a coordenação do IAU-USP em parceria com a FAU-USP, com apoio da Fapesp e do Condephaat, tem reunido extensa e diversificada documentação inédita que contribui ao estudo da arquitetura moderna brasileira e abre inúmeras oportunidades de pesquisa e de revisão da história desse período.

\section{PALAVRAS-CHAVE}

Arquitetura paulista. Arquitetura moderna. Patrimônio arquitetônico. 


\title{
INVENTORY OF CULTURAL ASSETS RELATING TO THE CARVALHO PINTO GOVERNMENT (1959-1963) ACTION PLAN. MÔNICA JUNQUEIRA DE CAMARGO'
}

\begin{abstract}
This inventory reveals the guidelines and actions of an important government plan never before investigated. The PAGE (Carvalho Pinto Government Action Plan) (1959-1963), aimed to create a democratic technocracy to rationalize public services and develop the State of São Paulo. The action plan's investments revolved around three sectors: 1) improving human conditions, this included education, culture and research; justice and security; public health and social care; and water and sewage systems; 2) infrastructure, this included power; railways; highways; municipal bridges; airports, ports and water transportation; and 3) agricultural expansion. As a result of these investments, over a thousand projects were created, involving about 160 architects, that have never been studied as a whole. No more than ten of the projects are known due to the notoriety of their authors, still they are never associated with PAGE. Scattered in hundreds of cities in the state of São Paulo, the documentation of these works is also spread throughout various public archives: IPESP; CPOS; SEF-USP; FDE; Departments of Agriculture and Health, as well as the archives of the architects themselves. Architectural magazines, the mainstream press and the testimonials of various stakeholders have revealed aspects both previously unknown and important to rebuild this process. This inventory was carried out under coordination of IAU-USP in partnership with FAU-USP, and support from Fapesp and Condephaat. It has gathered an extensive and diverse unpublished documentation that contributes to the study of modern Brazilian architecture and opens up numerous opportunities for research, as well as the review of this period's history.
\end{abstract}

\section{KEYWORDS}

Paulista architecture. Modern architecture. Architectural heritage. 
Inventário dos Bens Culturais relativos ao Plano de Ação do Governo Carvalho Pinto (1959-1963) apresenta alguns dos primeiros resultados do trabalho Difusão da Arquitetura Moderna no Brasil - O Patrimônio Arquitetônico Criado pelo Plano de Ação do Governo Carvalho Pinto (1959-1963), desenvolvido com o apoio do convênio firmado entre o Conselho de Defesa do Patrimônio Histórico Arqueológico, Artístico e Turístico (Condephaat) e Fundação de Amparo à Pesquisa do Estado de São Paulo (Fapesp, processo 2011/51108-0), no período de 01/03/2012 a 28/02/2014, sediado no Instituto de Arquitetura e Urbanismo-USP São Carlos, sob a coordenação do prof. Dr. Miguel Buzzar, com a participação de dezenas de pesquisadores $^{1}$, de graduandos a pós-doutorandos, com distintos comprometimentos de tempo e de mérito. O edital representou uma rara oportunidade de

\footnotetext{
1. Equipe de pesquisa: IAU-USP: Prof. Dr. Miguel Buzzar; Profa. Dra. Cibele Saliba Rizek; Prof. Dr. Francisco Sales Trajano Filho; Prof. Dr. Paulo Yassuhide Fujioka; FAU-USP: Profa. Dra. Monica Junqueira de Camargo; FCT-UNESP: Profa. Dra. Cristina Maria Baron Perissinoto; Profa. Dra. Arlete Maria Francisco; Prof. Dr. Evandro Fiorin; Prof. Dr. Hélio Hirao. Pesquisadores-doutores: Lucia Noemia Simoni; Maria Tereza Regina Leme de Barros Cordido; Doutorandas: Ana Cristina da Silva Araújo; Angélica Irene da Costa; Carolina Moreira Margarido; Gabriel Rodrigues; Mestres: Camila Lima Venanzi; Tânia Maria Bulhões Figueira; Graduandos: Arthur Policicio Rey; Daniela Gabriel de Paula; João Guilherme Bueno de Assis; Lucas Ambrozin Gallo; Victor Hugo Alves. Arquitetata Elaine Aparecida Jardim.
} 
aproximar pesquisas que vinham sendo desenvolvidas isoladamente pelos professores Miguel Buzzar e Monica Junqueira de Camargo, da Faculdade de Arquitetura e Urbanismo da USP.

O Plano de Ação do Governo Carvalho Pinto (1959-1963) - PAGE - foi uma experiência inédita em várias áreas - administração pública, política, educação, engenharia, arquitetura, e outras ainda a serem identificadas, para o qual não encontramos qualquer referência histórica. A partir de poucas informações dispersas que fomos alinhavando e o contato com alguns de seus participantes, chegamos a um extenso e rico acervo de documentos e obras, que nos permite afirmar tratar-se de uma iniciativa que deixou um grande legado em termos de planejamento e ação de governo, além da produção de um patrimônio arquitetônico com obras paradigmáticas da produção paulista que, entretanto, nunca foram associadas a esse plano de governo. $\mathrm{O}$ desconhecimento ou desprezo sobre essa iniciativa, até mesmo por alguns de seus participantes, é um paradoxo ainda a ser explicado.

\section{O PLANO}

O Plano de Ação do Governo Carvalho Pinto (PAGE) foi desenvolvido em um momento de expectativa de grandes mudanças econômicas, políticas e sociais e da consolidação da liderança do Estado de São Paulo no contexto brasileiro. Segundo o projeto apresentado (SÃO PAULO, 1959, p.15): "A década dos sessenta em São Paulo, deverá ser caracterizada pela definitiva transposição da barreira do subdesenvolvimento, cabendo-nos a responsabilidade de criar condições que facilitem essa evolução." Esse plano teve sua origem nas experiências da Sociedade de Análises Gráficas e Mecanográficas Aplicadas aos Complexos Sociais (Sagmacs), criada pelo padre francês Louis Joseph Lebret, fundador do Centro de Estudos Économie et Humanisme, que tinha por objetivo uma conciliação entre os interesses econômicos e o bem-estar social, tomando a realidade como premissa para o planejamento das cidades. Na SAGMACS Lebret:

elaborou uma série de pesquisas e planos urbanos e regionais, até a formulação da noção de Desenvolvimento Harmonizado que culminou com a fundação do IRFED - Institut International de Recherche et de Formation en vue du Développment Harmonisé, em 1958, que se dedicou à formação de técnicos especializados para atuar em 
projetos de desenvolvimento nos países considerados do Terceiro Mundo.” (ROLDAN, 2012,p.6)

Lebret veio ao Brasil pela primeira vez em 1947 para dar um curso na Escola Livre de Sociologia e Política, do qual participaram, entre outros: Lucas Nogueira Garcez, Luís Cintra do Padro e André Franco Montoro. Em 1952, Lucas Nogueira Garcez, então governador do Estado de São Paulo, contratou a Sagmacs para um estudo sobre as possibilidades de desenvolvimento do Estado de São Paulo, tendo em vista o projeto da bacia do rio Paraná, do qual participaram, além de Lebret, Antonio Bezerra Baltar, Frei Benevenuto de Santa Cruz, entre outros. Os desenhos de mapas e gráficos foram realizados por arquitetos recém-formados: Clementina d'Ambrosis, Miguel Zangaro, Joaquim Guedes, Liliana Guedes e Domingos de Azevedo Netto, (ROLDAN, 2012, p.125). Os três últimos, alguns anos mais tarde, participariam do PAGE.

Carvalho Pinto foi eleito pelo Partido Democrata Cristão (PDC) e teve como primeira medida aprovar seu Plano de Ação, que foi instituído pelo Decreto no 34.656, de 12/02/1959. Nesse decreto fica claro o seu objetivo de levar o progresso ao conjunto do Estado com a implantação e construção de serviços e equipamentos sociais, através de "um Plano de Govêrno, que demarque objetivos, determine prioridade e fixe tempo de execução". O PAGE tinha a ambição de criar uma tecnocracia democrática para racionalizar o serviço público e promover o desenvolvimento do Estado de São Paulo. O texto de apresentação do PAGE à Assembleia evidencia a sua filiação às ideias lebretianas, valendo-se várias vezes da ideia de harmonização para conciliar o desenvolvimento econômico com melhoria social. Seja ao explicar a função do estado (p.17): “(...) 'harmonizar' a conjugação dos fatores de produção da sociedade de molde a obter deles o melhor rendimento social." Seja na explicação da concepção do plano (p.18):

Seu objetivo geral, como bem evidencia o seu conteúdo, é o de melhoria, aperfeiçoamento e atualização das atividades do Estado, colocando-as no nível necessário ao progresso paulista. Dirige-se a dois grandes grupos de finalidades: Investimentos para a melhoria das condições do Homem e Investimentos para a promoção do 
desenvolvimento. Enquadra-se, assim, o Plano em uma concepção integral e harmônica de desenvolvimento econômico e social.

O PAGE foi estruturado a partir das necessidades e demandas de todos os órgãos da administração estadual que tiveram a oportunidade de apresentar os seus problemas fundamentais relacionados à execução de obras e serviços, aos quais foram feitas propostas visando solucioná-los dentro de uma programação para os quatro anos de governo.

\footnotetext{
Essa documentação - que representa o acervo de conhecimento e experiência de todos aqueles que estão em permanente contato com as questões e problemas que devem ser resolvidos pela Administração Estadual - serviu de base e foi incorporada ao Plano elaborado pelo Grupo de Planejamento. Credencia-se, assim, o Plano por espelhar o máximo de realismo possível, fundamentado que está no conhecimento direto que têm da realidade paulista os funcionários públicos estaduais, em cada setor de atividade.
}

Apesar da declarada valorização do conhecimento técnico do funcionalismo público, o PAGE foi responsável pela contratação de centenas de arquitetos autônomos, um número até então nunca verificado em administrações anteriores por meio de um inédito e polêmico acordo com o Instituto dos Arquitetos do Brasil (IAB-SP). Contemporâneo às obras da nova capital do país, que selou com grande ênfase a associação da arquitetura com a imagem de progresso e modernidade, o PAGE também se propôs promover o desenvolvimento do Estado, valorizando a arquitetura paulista. Tal relação - deflagrada com muito sucesso com o projeto do Ministério da Educação e Saúde Pública, de 1936, e reiteradamente afirmada pelas obras que marcaram a trajetória política de Juscelino Kubitschek, culminando com a construção de Brasília - revela a afinidade de Carvalho Pinto com as estratégias políticas em curso e esclarece a distinção dada à arquitetura no seu plano. A incorporação de arquitetos que tinham trabalhado na Sagmacs, ativos no IAB-SP e próximos aos professores, especialmente a Vilanova Artigas, fortaleceu a relação entre a arquitetura e o Plano. Tal proximidade, frente às ambições do Plano e à confiança na representatividade 
da arquitetura, favoreceu essa contratação de profissionais externos ao serviço público para o desenvolvimento de cerca de mil projetos.

O Plano estruturou-se funcionalmente em duas equipes: um grupo de Planejamento ${ }^{1}$, instituído pelo mesmo decreto, sob a coordenação de Plínio de Arruda Sampaio, e um grupo técnico com profissionais de várias áreas ${ }^{2}$, ambos diretamente relacionados ao governador. O Grupo de Planejamento contou inicialmente com os seguintes profissionais: Plínio Soares de Arruda Sampaio (coordenador); Diogo Adolho Nunes Gaspar (economista, secretário executivo); Celeste Angela de Souza Andrade (diretor geral do Departamento de Estatística do Estado); Paulo Menezes Mendes da Rocha (professor catedrático da Escola Politécnica-USP); Ruy Aguiar da Silva Leme (professor catedrático da Escola Politécnica-USP); Antônio Delfim Netto (assistente da Faculdade de Ciências Econômicas e Administrativas-USP); Sebastião Advíncula da Cunha (Departamento Econômico do BNDE); Orestes Gonçalves (chefe do Gabinete de Estudos Econômicos e Financeiros da Secretaria da Fazenda); Ruy Miller Paiva (engenheiro agrônomo do Departamento da Produção Vegetal da Secretaria da Agricultura). O Grupo Técnico (GT) era composto por: Mário Laranjeira de Mendonça, Celso Monteiro Lamparelli, Francisco Whitaker Ferreira, Domingos Theodoro de Azevedo Netto, Henrique Silveira de Almeida, Antonio Amílcar de Oliveira Lima, José Reinaldo Gomes e Pedro Penteado Nogueira.

Com base nos princípios do Planejamento-Orçamento, o governo aprovou na Assembleia Legislativa o Plano Plurianual de Orçamento, que permitia ao executivo implementar suas metas sem outras negociações com o Legislativo. Do ponto de pista dos investimentos, o PAGE foi organizado em três setores: 1- melhoria das condições do homem, que incluía as áreas de educação; cultura e pesquisa; justiça e segurança; saúde pública e assistência social; e sistemas de água e esgoto; 2- infraestrutura, abrangendo energia; ferrovias; rodovias; pontes municipais; aeroportos, portos e navegação; e 3- expansão agrícola e industrial, que cobriria as demandas de armazenagem e ensilagem, e de abastecimento, que criaria uma rede de experimentação e fomento agropecuário e que incentivaria a criação da grande indústria de base. 
FIGURA 1

Gráfico do Plano Fonte : SÃO PAULO

Estado. Governo

Carvalho Pinto.

Plano de Ação (1959-1963). p. 44

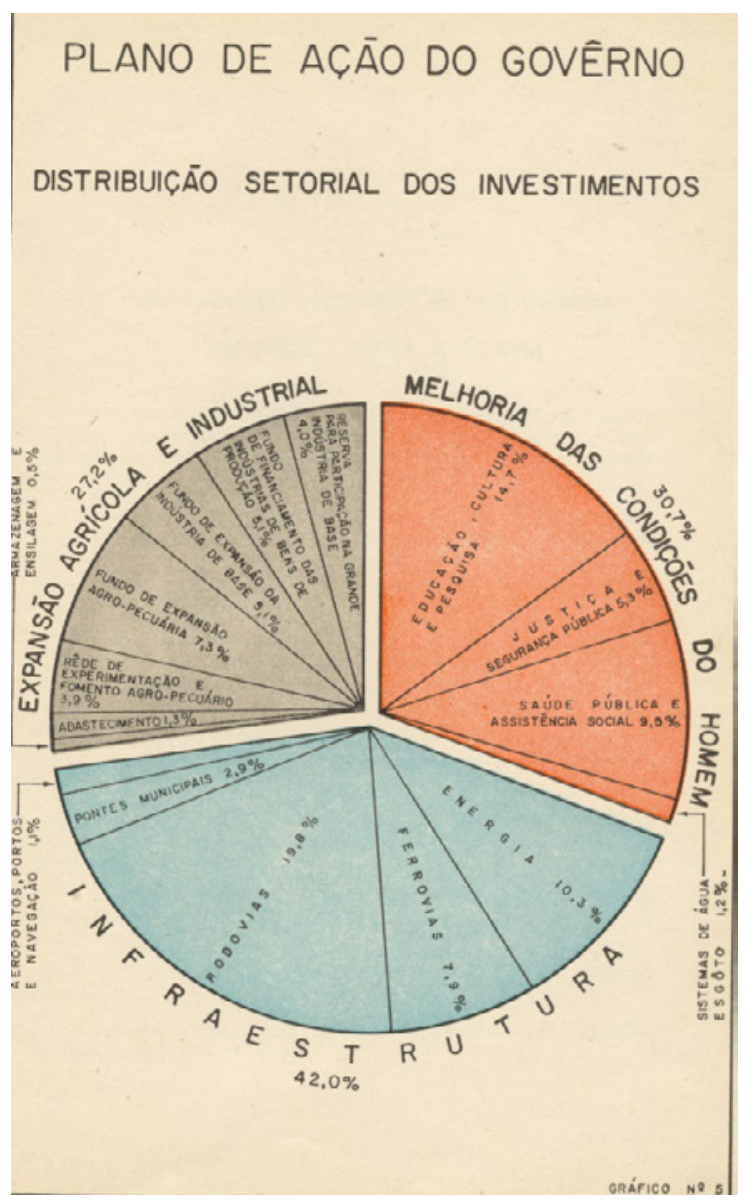

Para o cumprimento dessas metas foram criados os Fundos: de Construção Escolar (FECE), de Construção da Cidade Universitária (FCUASO), de Expansão Agropecuária, de Expansão da Indústria de Base e de financiamento das indústrias de bens de produção. Previu-se a subscrição de ações do Banco do Estado de São Paulo, da Companhia Hidroelétrica do Rio Pardo, das Usinas Elétricas de Paranapanema, da Companhia de Armazéns Gerais do Estado para organizar um Centro Estadual de Abastecimento (atual CEAGESP) para a área metropolitana da capital. No campo da infraestrutura energética, o Plano também propiciou o início da construção da Usina Hidrelétrica de Urubupungá, a realização das obras nas usinas de Limoeiro, Euclides da Cunha, Barra Bonita, Jurumirim, Bariri, Graminha e Xavantes. 
Com um terço dos recursos destinado à melhoria das condições do homem, dos quais a metade (correspondendo a $14 \%$ do total previsto), para a educação, cultura e pesquisa, houve um grande investimento na construção de equipamentos públicos: fóruns, postos de saúde e principalmente de escolas (primárias, secundárias, técnicas profissionais) e na construção da Cidade Universitária Armando Salles de Oliveira, que vinha se arrastando há décadas, além da criação de uma nova instituição, a Universidade Estadual de Campinas, e de um órgão de apoio à pesquisa - a Fapesp.

No campo da arquitetura, esses projetos, frente ao desafio proposto, tomaram a feição de experiências pilotos das possibilidades da arquitetura em todos os seus aspectos, cujo resgate e preservação é um compromisso com a história da arquitetura. Nem os arquitetos, com raras exceções, ao comentar essas obras enfatizam seu vínculo com essa política pública, tampouco os historiadores as associam como integrantes de um conjunto, destacando quase sempre a contribuição de cada uma delas como se tivessem sido concebidas independentemente. $\mathrm{O}$ reconhecimento das imbricadas conexões entre essas obras e o contexto político, social e econômico de sua época abre uma ampla perspectiva de investigação que permitirá inúmeras leituras que trarão novas questões que, por sua vez darão outra dimensão de seu significado histórico.

No campo da administração pública, da política, da economia e do desenvolvimento social, a extensa documentação relativa a esse plano ainda precisa ser estudada, cujo inventário iniciado poderá contribuir.

\section{INVENTÁRIO}

Considerando nossas áreas de interesse, concentramo-nos no levantamento do acervo arquitetônico produzido no âmbito do PAGE, selecionando os arquivos relativos a essas obras. Importante ressaltar que há outros que não foram perscrutados e certamente têm informações preciosas para o estudo e a produção desse período, como a secretaria de vias e estradas de rodagem, de infraestrutura, do abastecimento, da saúde etc. Nosso objetivo consistia na identificação das obras de arquitetura projetadas e realizadas: quantas, quais, onde e quando foram contratadas e/ou realizadas, recuperando a documentação existente, promovendo a visita de campo, confrontando as informações de modo a permitir o redesenho e construção tridimensional dessas obras. Considerando o tempo proposto pelo edital, consideramos inicialmente a análise de 100 obras. 
A falta de fortuna crítica sobre o PAGE e a dispersão de sua documentação obrigou-nos a estruturar a pesquisa em várias frentes de ação simultâneas: levantamento bibliográfico, de acervos, entrevistas e visitas às obras, cada qual nos fornecia novas referências sobre o PAGE, cujo cruzamento levava-nos a retomá-los à busca de comprovações e/ou de novas informações. Trata-se de uma pesquisa essencialmente com fontes primárias e levantamento de campo. A primeira etapa consistiu no conhecimento do Plano, através dos registros existentes, da produção historiográfica sobre o mesmo e das pessoas envolvidas que pudessem abrir pistas à investigação.

\subsection{Levantamento Bibliográfico}

Sobre o Plano há pouco registro, estudo ou pesquisa. Os textos basicamente são a própria apresentação do Plano de 1959 e os seus relatórios na forma de Mensagem à Assembleia Legislativa de 1960, 1961 e 1962. Tais documentos constituem as únicas informações escritas sobre os seus objetivos e orçamentos, não encontramos nenhum estudo sobre a proposta ou sobre seus resultados, a não ser as notícias e algumas análises críticas da grande imprensa à época de seu lançamento, alguns comentários esparsos e as entrevistas dos participantes.

Os quatro documentos oficiais - Governo Carvalho Pinto - Plano de Ação 1959-1963 (a proposta em si) e os três relatórios anuais enviados à câmara - além da apresentação dos objetivos a serem alcançados, trazem considerações sobre os conceitos adotados, sobre o planejamento e suas etapas, esclarecimentos sobre as áreas sob o controle do poder estadual, o papel e a função do Estado na promoção do desenvolvimento e informações sobre investimentos.

$\mathrm{O}$ volume relativo à apresentação do Plano é constituído de seis capítulos, tendo com abertura a proposta para o projeto de lei que institui o Plano. Os capítulos são: Planejamento e Atividade do Governo; Uma Análise da Economia Paulista; Objetivos do Plano de Ação; Recursos necessários ao Plano de Ação; Plano e Responsabilidade Política.

Os relatórios anuais apresentam os seguintes conteúdos: Introdução; Plano de Ação; Educação, Cultura e Pesquisa; Justiça e Segurança Pública, Saúde Pública e Assistência Social; Saneamento; Trabalho, Previdência e Habitação; Energia Elétrica; Transportes e Comunicações; Agricultura; Administração fazendária; Assessoramento Técnico ao Governador; Estatística; Trabalhos Gráficos; Material Excedente e Especificação das Obras do Plano de Ação. 
Os planos setoriais são embasados em levantamentos da situação existente, apresentados através de gráficos, quadros e tabelas, buscando espelhar o máximo de realismo. Essas questões que, se analisadas hoje, podem parecer absolutamente primárias, dão a dimensão da novidade de tal atitude para época, inclusive tendo sido necessário comentar em determinado momento que:

O Plano, a par de inovações metodológicas introduzidas em sua elaboração situa-se em "área de programação" quase inexplorada na tradição brasileira. Seu objetivo geral, como bem evidencia o seu conteúdo, é o de melhoria, aperfeiçoamento e atualização das atividades do Estado, colocando-as no nível necessário ao progresso paulista. (...) pretendeu-se com o método de planejamento adotado, eliminar concepções errôneas sobre essa técnica de trabalho. Em primeiro lugar, a decisão de planejar não implica em paralisação das atividades do estado: ao contrário, ao obrigar um adensamento da percepção da realidade, possibilita o aceleramento de obras em curso e mesmo o início de obras novas, bem como provoca medidas administrativas imediatas. Em segundo lugar, o Plano não é apenas um documento que se elabora uma vez e passa a ter existência estática. $\mathrm{O}$ documento inicial é apenas um recorte seccional na realidade, dinâmica e mutável, onde se indica a maneira pela qual se apreende esta mesma realidade, expressa-se a concepção política a ser seguida, enumerando-se os objetivos a serem atingidos, no seu prazo, bem como se estabelece escala de prioridade para a execução de obras e serviços e dá-se um primeiro balanço nas fontes de recursos capazes de serem mobilizados para o programa, face às exigências de dispêndios. ${ }^{2}$

A organização do Plano de modo estruturado e a clareza na apresentação da proposta, de seus conceitos, objetivos e metas, facilitou sua divulgação e disseminação, com repercussão em vários estados do país. Embora seus conceitos e metodologia tenham sido incorporados na administração pública pelo país afora, como já comentamos, raramente foram creditados ao PAGE.

2. Idem, p.18 e 20 . 
$\mathrm{Na}$ grande imprensa, segundo levantamento realizado pelos pesquisadores em três dos principais jornais em circulação durante os anos de 1959 a 1963 (O Globo, do Rio de Janeiro e os periódicos O Estado de S. Paulo e a Folha de S. Paulo, de São Paulo, que a partir de janeiro de 1960 assumiu esse título, agregando a Folha da Manhã e a Folha da Noite), foi possível verificar ampla divulgação dessa iniciativa. A pesquisa foi feita via arquivo eletrônico, utilizando as palavras-chaves: plano de ação; plano de ação do governo e Carvalho Pinto.

$\mathrm{Na}$ extensa cobertura dada à apresentação oficial do PAGE, em 9 de julho de 1959, e nos dias seguintes, os jornais destacaram a iniciativa inovadora da nova gestão, demonstrando certo receio de sua receptividade pelos políticos que poderiam sentir-se cerceados nas suas negociações, uma vez que sua aprovação plurianual garantiria o comprometimento da verba orçamentária, dificultando os desvios futuros. Percebe-se pelo tom das reportagens um apoio e um comprometimento da imprensa em buscar a adesão do legislativo às propostas do executivo.

A análise crítica mais detalhada foi levada à frente pela Folha da Manhã que, ao longo de um mês - de 18 de julho a 16 de agosto de 1959 - publicou diariamente no seu caderno Economia e Política um artigo sob o título O Plano de Ação do Governo Paulista, com o claro objetivo de contribuir para sua real implantação, apontando as possíveis falhas, corrigindo as falhas identificadas, conforme notícia da primeira página do jornal do dia 17 de julho (Figura 2).

\section{AS "FOLHAS" ANALISAM O PLANO DE AÇÃO DO GOVERNO PAULISTA}

A partir de amanhã as FOLHAS iniciarão a analise pormenori:ada do Plano de Açăo do governo do Estado, procurando efetuar uma critica objetiva e construtiva, dentro das normas tradicionais de atuaçăo de nossos jornais, que visam, sobretudo, ao esclarecimento da opiniào publica, independentemcnte de posiçóes politicas ou de outra naturesa.

A analise em referencia estura a cargo da equipe de redatores especialisados das FOLHAS, que trabalham em conjunlo, procurando efetuar um exame dos varios selores abrangidos pelo plano sem perder de vista o nexo logico e $a$ necessaria interdependencia dos varios problemas.

Com uma critica pormenorisada e global do Plann de Acä̃o experamos contribuir para a correção de eventuais falhas desse trabalho, bem como farorecer uma colocação dos îroblemas administrativos de nossa terra em termos serios $e$ objetivos. 
O conjunto de 26 artigos $^{3}$ constitui, portanto, a análise mais detalhada do Plano a que tivemos acesso.

Apoiado pelas representações dos vários setores produtivos, pelos sindicatos e por partidos políticos, inclusive com o elogio do presidente Juscelino Kubistchek na edição do dia 2 de agosto de 1959, o PAGE foi alvo também da crítica da oposição, que se manifestou na edição do dia 27 de agosto de 1959, no jornal O Estado de S.Paulo sob a manchete Opina a oposição sobre o Plano de Governo. A matéria apresenta a contestação de um deputado da oposição alegando sua constitucionalidade e sua falta de comprometimento com a realidade do Estado.

O impacto inicial do Plano que gerou muitas notícias, ora comentando sua viabilidade executiva, ora destacando a atenção dada a certos setores, especialmente à educação, à medida que a nova gestão foi se tornando rotina, a euforia foi arrefecendo e o interesse passou a ser esporádico tanto a favor como contra, seja noticiando a implantação de algumas medidas seja registrando a insatisfação de certos prefeitos que se sentiam desamparados pelos recursos do governo, ou de outros que exigiam maior

3. - 18/07, Conceituação e delimitação dos objetivos; 19/07, Método de financiamento, origem e montante dos recursos previstos; 21/07, Esforço de vulto para melhorar as condições do ensino, embora insuficiente e mesmo simplista em certos pontos; 22/07, Recursos insuficientes para a obra de difusão cultural que se reclama; 23/07, Imprescindível o estímulo às vocações científicas para aproveitar os recursos reservados à pesquisa; 24/07, Insatisfatório o plano governamental na parte relativa à justiça è à segurança; $25 / 07$, Embora suficiente em si mesmo, não basta simples aparelhamento material da polícia; 26/07, Mal colocados os problemas dos menores infratores e abandonados; 28/07, Medidas positivas de assistências aos enfermos ao lado de falhas na prevenção de graves males; 29/07, A simples programação de obras não possibilita uma solução satisfatória dos problemas de água e esgoto; 30/07, Apesar de ter a envergadura necessária, o planejamento no setor de energia peca pela omissão de Caraguatatuba; 31/07, Deve-se esperar grande melhoria na capacidade de transporte ferroviário; $01 / 08$ - No setor rodoviário o governo modifica a orientação anterior e socorre o DER; 02/08, As obras de Viracopos polarizam as atenções do programa aeroportuário; 04/08, As mudanças gerais de infraestrutura e das condições do homem e a importância relativa de sua influência nos meios rurais; 05/08, Embora se constitua em fator de estímulo à cultura dos cereais, a rede de silos não cobrirá algumas zonas produtoras do Estado; 06/08, De feitio conservador as medidas projetadas para a rede de experimentação e fomento agropecuários; 07/08, Medidas insuficientes no setor florestal, mas expressivas como abertura de nova era; 08/08, Fundo agropecuário: iniciativa pioneira, cujo êxito depende de fatores que ampliem e aprofundem sua ação; 09/08, Colocação de um problema e observações finais sobre o funcionamento do fundo agropecuário; 11/08, Pode-se prever marcada influência dos investimentos de infraestrutura na expansão industrial paulista; $12 / 08$, Iniciativa merecedora do melhor aplauso, o fundo de expansão da indústria de base exige, entretanto, urgente planejamento; 13/08, Modesto em seus recursos e limitado no funcionamento, ainda assim o Fundo da Indústria de Bens de Produção constitui louvável esforço; 14/08, Torna-se efetiva a participação do Estado na expansão do parque industrial paulista; 15/08 - Impõe-se urgente complementação: plano de reforma administrativa; 16/08, As implicações políticas do planejamento e a atitude que se deseja da Assembleia. 
celeridade no andamento das obras. Sobre a arquitetura desse período vale destacar os artigos Uma nova Arquitetura nas obras públicas de S. Paulo, do Estado de S. Paulo, 17 de jul. 1960; A integração arquitetônica valoriza os projetos da cidade Universitária, da Folha de S. Paulo, 18 de abr. 1961. No levantamento da imprensa especializada em arquitetura, a pesquisa concentrou-se nas revistas Acrópole e Habitat, tendo identificado 54 matérias sobre as obras do PAGE e poucas referências ao próprio plano, das quais destacamos o editorial da revista Acrópole n. 249, de julho de 1959:

\footnotetext{
Travando contato com o atual plano de ação do governo, previsto para o quinquênio 1959-1963, sentimos interesse da Administração Estadual em desenvolver um programa capaz de tornar a ação oficial mais rápida, completa e adequada à solução dos problemas públicos, a cujo serviço se encontra o Estado. Assim é que o plano no campo da construção deverá se expandir através de edificações para fins múltiplos.
}

Para a aferição do incremento de projetos públicos realizados, a pesquisa estendeu o período investigado que antecedeu e sucedeu o plano, verificando que houve um considerável aumento no período vigente ou decorrente do Plano, pois muitos projetos só foram concluídos após a saída de Carvalho Pinto. Os quadros e tabelas referentes a esse levantamento estão disponíveis no site: <http://www.iau.usp.br/pesquisa/grupos/artarqbr/ planodeacao/index.php/pesquisa $>$.

Em 1962, o periódico America Magazine publica um número especial sobre Cidade Universitária Armando Salles de Oliveira com o objetivo de apresentar as obras contratadas pelo PAGE e a trazer a público os investimentos realizados no campus. Trata-se de um precioso documento sobre o campus, com levantamento e fotos inéditas, que nos foi emprestado por Carlos Alberto Felizola Freire, membro da Comissão Técnica responsável pelo FCRCUASO. A publicação, sem numeração de páginas e intercalada com muita propaganda, é composta das seguintes matérias: Edição Especial Cidade Universitária Armando Salles de Oliveira: um breve editorial, assinado pelo redator Dr. A. Berwid; Integração Universitária - um trecho do discurso de posse do reitor Prof. Dr. Antonio de Barros Ulhoa Cintra, no dia 16 de junho de 1960, no qual expõe a origem da USP em cursos isolados e a necessidade de integrá-los 
como uma Universidade; o artigo seguinte é o mais extenso, tendo como conteúdo a apresentação do planejamento do novo campus, situando-o historicamente no contexto do ensino universitário brasileiro e frente ao Plano de Ação, a setorização por áreas do conhecimento, as obras em execução e o projetos contratados, ilustrada com fotos e desenhos.

A primeira referência historiográfica encontrada sobre o PAGE foi uma rápida e equivocada citação em um artigo de Vilanova Artigas, Sobre Escolas, publicado na revista Acrópole em setembro de 1970, republicado em Caminhos da Arquitetura, em 2004, pela editora Cosac\&Naify, e comentado por Alves no seu artigo As implicações historiográficas da consulta às fontes primárias no estudo da arquitetura escolar pública paulista (19591962), publicado na revista FÓRUM, edição de 2011. Neste texto, Artigas (1970, p.13) analisa o panorama das construções escolares no Brasil, e refere-se muito rapidamente ao Fundo de Construção Escolar (FECE), criado no âmbito do PAGE, identificado, graças a uma confusão feita por Artigas, como Plano de Desenvolvimento Integrado (PLADI) que é uma proposta desenvolvida pelo governador Adhemar de Barros, seu sucessor que derrotou o seu candidato José Bonifácio Coutinho Nogueira. A maneira a qual se refere ao PAGE é tão distante quanto às propostas das escolas republicanas, sem qualquer comentário ao seu envolvimento com esse plano, nem aos projetos que desenvolveu:

Em 1960 abandonaram-se os organismos promotores de projeto e construção que vinham sendo usados e criou-se um novo organismo central de programação - o FECE (Fundo de Construções Escolares). (...) O PLADI, Plano de Ação e Desenvolvimento Integrado, do governo Carvalho Pinto, "Plano de Ação" como era conhecido, descreveu a situação em que nos encontrávamos...

(...) Um plano de emergência como se vê. Para a emergência, os órgãos de projeção do estado não estavam aparelhados. Para ajudá-los, resolveu-se atribuir projetos a arquitetos de fora da estrutura do funcionalismo público. Já tinham uma experiência técnica, acumulada a duras penas, realizando obras particulares. Assim foi projetado, em tempo relativamente curto, um conjunto apreciável de escolas, e a sociedade tomou conhecimento da existência dessa reserva técnica que são os quadros da arquitetura paulista. Trabalham por honorários mediante os 
quais "arquitetos de outros países não moveriam um dedo" - como disse revista estrangeira que a eles se referiu.

Cabe destacar que Artigas teve papel de destaque no acordo entre IAB e o Grupo de Planejamento do PAGE, conforme atas do IAB, com registros dos debates ocorridos entre os associados sobre esse acordo nas atas dos dias 24/02/1959; 10/08/1959; 20/08/1959 e 08/09/1959. Na ata da reunião do dia 08/09/1959, consta como primeiro item da ordem do dia: relação profissional entre arquitetos e o Instituto de Previdência do Estado de São Paulo (Ipesp). Este item da pauta gerou manifestações favoráveis de Rubens Carneiro Viana, Jorge Wilheim e de Vilanova Artigas que justificou as remunerações injustas como um passo à frente no processo de reconhecimento ao arquiteto como profissional, devendo o IAB adotar uma posição estratégica frente a essa oportunidade. Aqueles que se manifestaram contrariamente - Ruy Gama, Francisco Ferreira, Luis Saia e João Clodomiro de Abreu - defendiam o fortalecimento dos quadros profissionais dos órgãos públicos. Tal debate acabou gerando um documento conciliador das duas posições:

\footnotetext{
A Assembleia autoriza a Diretoria do IAB a promover junto aos órgãos do governo os entendimentos necessários para ampliar cada vez mais as medidas que vem sendo tomadas no sentido de empregar o esforço criador dos arquitetos paulistas nas obras públicas ao significado cultural da arquitetura brasileira e encarecer a necessidade do governo de se aparelhar de uma equipe de técnicos capazes de levar a bom termo o planejamento de suas obras.
}

Outra referência ao Plano foi sugerida por um dos nossos entrevistados, Jorge Yori. Trata-se do capítulo A experiência Regional de Planejamento, escrito por José Roberto Mendonça de Barros, do livro Planejamento no Brasil, organizado por Betty Mindlin em 1974. Tratado como um plano regional, Barros (1974 p. 111 a 137) analisa-o do ponto de vista do desenvolvimento econômico, destacando seu pioneirismo e sua viabilidade dada, a privilegiada capacidade produtiva e econômica do Estado de São Paulo, que lhe garantia certa autonomia em relação à administração federal. Segundo Barros (1974:135) o sucesso do Plano deve-se paradoxalmente à mesma razão que o 
levou ao esquecimento, qual seja a da sua autonomia em relação à estrutura pública. Como Carvalho Pinto não conseguiu eleger seu sucessor, a estrutura montada foi desarticulada com sua saída. Os desdobramentos políticos seguintes, sua adesão ao governo João Goulart como Ministro da Fazenda, sua posterior ruptura apoiando as forças que o depuseram e sua filiação à Aliança Renovadora Nacional, comprometeram a defesa de suas ideias.

Sob a ótica da administração pública, encontramos um primeiro e único trabalho, ${ }^{4}$ Carvalho Pinto: trajetória e projeto político, de Ana Beatriz da Silva Gordo Lang, de 1991. Trata-se de uma pesquisa desenvolvida para o Centro de Estudos Rurais e Urbanos da FFLCH-USP (CERU), com apoio do CNPq. A pesquisa foi estruturada com base na metodologia de memória oral, que visava entrevistar Carvalho Pinto sobre sua trajetória com especial atenção ao seu Plano de Governo, entretanto, o governador morreu dias antes da gravação oficial. Lang recuperou o roteiro por ele elaborado para a entrevista, bem como todos os contatos necessários que a antecederam visando sua preparação, que foram registrados no referido trabalho.

$\mathrm{Na}$ área da Arquitetura, a partir de 2004, o Plano de Ação passou a merecer alguma atenção em alguns trabalhos acadêmicos, seja na forma de pequenas notas, capítulos até trabalhos monográficos e comunicações de congressos. O doutorado de 2004, com base em desenhos da SEF, redesenha os vários planos e projetos e recupera parte importante da documentação do campus. É a primeira recuperação arquitetônica do setor das ciências humanas, constituído de projetos referenciais da história da arquitetura que nunca tinham sido publicados no seu conjunto. Os seis projetos que integrariam esse setor foram contratados com arquitetos professores da FAU, dos quais apenas dois foram construídos segundo os projetos originais, dois tiveram as fundações executadas e dois nunca saíram do papel. A partir do documento Planejamento elaborado pelo Escritório Técnico Administrativo de 1963 (CABRAL, 2004, p. 179) e dos projetos isolados de cada um dos edifícios, garimpados em

\footnotetext{
4. Este trabalho nos foi emprestado pelo coordenador do Plano, Plínio de Arruda Sampaio, mas não consta do catálogo virtual de nenhuma biblioteca universitária, ao menos daquelas que oferecem mais amplo acesso.
} 
distintas fontes, Neyde Cabral (2004, p.191) os integrou em um único desenho, que não havia sido antes elaborado ou pelo menos ainda não foi encontrado nenhum registro.

Para uma visão dos espaços que um pedestre atravessaria, caso se deslocasse entre os edifícios projetados para o Setor das Humanas na década de sessenta, elaboramos uma planta do conjunto com os pavimentos térreos inseridos em suas localizações, e um corte longitudinal.

(CABRAL, 2004, p.182)

Em 2006, Arquitetura Escolar Paulista Anos 1950 e 1960, organizada por Avany de Francisco Ferreira e Mirela Geiger de Mello, encontram-se as primeiras análises críticas sobre as escolas do PAGE, na apresentação das organizadoras e no artigo de Janice Theodoro da Silva - A construção da cidadania e da escola nas décadas de 1950 e 1960. Essas autoras enfatizam a preocupação meramente quantitativa do Plano, a ausência de uma proposta pedagógica de base que orientasse a construção desses espaços e o distanciamento entre pedagogos e arquitetos reforçado pela contratação de escritório particulares. A análise de Janice T. da Silva (2006, p. 48) restringe o Plano de Ação à construção de escolas:

Em 1959, frente às pressões políticas, o governador Carvalho Pinto (1910-1987) e sua equipe elaboraram o chamado Plano de Ação para a área educacional. Esse plano visava a toda a demanda de ensino primário do estado, incorporando a totalidade das crianças em idade escolar. Ao mesmo tempo o plano propunha um período maior de permanência dos alunos na escola. Apesar dos quase 600 prédios escolares construídos pelo IPESP, as metas iniciais não foram cumpridas integralmente, sobretudo nas zonas rurais do Estado. Além disso, a política educacional esteve voltada, basicamente para a inclusão do aluno na escola, sem que se discutisse o que seria uma educação de qualidade.

Entretanto, a autora passa a discorrer sobre o compromisso político de alguns arquitetos, especialmente Vilanova Artigas, cujos projetos expressam um novo conceito de escola, com mínimo de fronteiras entre alunos e professores e entre a escola e a comunidade, ao que se pode inferir um projeto 
também pedagógico. $\mathrm{O}$ artigo de Wisnik, que se referencia no texto Sobre escolas, de Artigas, corrobora a referência equivocada ao PLADI no lugar de PAGE e destaca também, como Janice T. Silva, o caráter inovador dos espaços escolares dentro de uma vasta produção ainda longe de ser homogênea, mas que constitui a base da Escola Paulista de arquitetura.

Os trabalhos acadêmicos de Maria Tereza Cordido, mestrado de 2007, cujo tema é a arquitetura forense, e o de André A. A. Alves, doutorado de 2008, sobre as escolas do IPESP, ambos desenvolvidos a partir de fontes primárias e levantamento de campo, constituem as primeiras leituras sobre esses objetos arquitetônicos como documentos históricos do Plano, a partir dos quais é possível a compreensão das ideias e do contexto que lhes deram origem, trazendo a público uma vasta documentação que já tem suscitado algumas revisões e certamente ampliará o leque de perscrutações sobre a história desse período. A análise de Daniele Pisani sobre a obra de Paulos Mendes da Rocha, publicada pela $G G$ em 2013, comprova a contribuição dessas pesquisas. Pela primeira vez no estudo de arquitetos atuantes nesse período, suas obras foram relacionadas ao PAGE. Pisani, no capítulo 2 - Arquitetura paulista, semelhança de família - abre um subtítulo: $O$ Plano de Ação do Carvalho Pinto, escolas de arquitetura paulistas em vez de escola de arquitetura paulista, onde, com base no trabalho de Alves, introduz o significado do Plano de Ação na trajetória de Mendes da Rocha e sua relação com a Escola Paulista. Por ter tido como base o trabalho de Alves, concentra-se nas escolas, faz uma rápida retrospectiva do quadro paulista comparando a produção do PAGE com a iniciativa anterior do Convênio Escolar 1949-1954. Estende a análise à participação de Artigas e do grupo a sua volta, distinguindo a produção desse grupo com alguma similaridade frente à diversidade do restante da produção promovida pelo Plano.

Alguns resultados parciais foram publicados e apresentados em reuniões científicas, cujas referências encontram-se na bibliografia deste trabalho.

\subsection{Entrevistas}

Como mencionamos na apresentação, a carência de referências bibliográficas nos levou a procurar aqueles que participaram do PAGE, cujos 
depoimentos foram fundamentais para a compreensão do Plano e sua dimensão. De algumas pessoas há mais de um depoimento, pois foram entrevistadas separadamente pela equipe coordenada por Miguel Buzzar e por Mônica Junqueira de Camargo, quando desenvolviam suas pesquisas separadamente, como Plínio de Arruda Sampaio (coordenador do Grupo de Planejamento), Celso Lamparelli, (arquiteto, membro do grupo técnico, responsável pela área da educação), Fábio Penteado (arquiteto de projetos contratados pelo Plano). Ao todo foram entrevistados 15 participantes do PAGE, dos quais os mais produtivos à sua compreensão são:

Domingos Theodoro de Azevedo (arquiteto, membro do grupo técnico e responsável pela área da saúde, antes tinha trabalhado com Padre Lebret na SAGMACS); Bernardo Castelo Branco (arquiteto, professor da FAU-USP, diretor de Divisão de Projetos da Secretaria da Agricultura e Abastecimento à época, tendo sido responsável por vários projetos do Plano); Ivan Gilberto Castaldi (arquiteto, desenvolveu projetos para o PAGE); Antonio, Delfim Neto (membro da equipe de planejamento, professor assistente da Faculdade de Economia da Universidade de São Paulo); Francisco Whitaker Ferreira (arquiteto, responsável pela área de Justiça e Segurança Pública); Carlos Alberto Felizola Freire (membro da equipe técnica, responsável pelo FCCUASO); Jorge Hori (membro da equipe técnica, até então técnico do BNDE, responsável pela estrutura econômica e de controle do PAGE); João Honório de Mello Filho (arquiteto, membro da equipe técnica na área de educação); Paulo Mendes da Rocha (arquiteto, autor de projetos para o PAGE); Maria Giselda Cardoso Visconti (arquiteta, trabalhou na equipe técnica na área de educação).

Essas entrevistas foram transcritas, integram o relatório entregue à Fapesp e ao Condephaat, e serão disponibilizadas na página virtual da pesquisa, tão logo o projeto do site esteja totalmente concluído. São depoimentos históricos com informações inéditas não só do PAGE, mas da história desse período brasileiro. Cada um deles estabeleceu relações inusitadas com o momento em que viviam. A maioria dos entrevistados mostrou-se surpresa com a recuperação histórica do Plano, sobre o qual não haviam mais ouvido qualquer comentário. Com certo esforço para "relembrar questões adormecidas", todos falaram com muito prazer e entusiasmo desse período e do próprio trabalho. Foi possível apreender dos 
vários depoimentos que a contribuição do PAGE nas diversas áreas foi a oportunidade de se concretizar ideias que vinham sendo debatidas e não tinham apoio para serem levadas à frente. $\mathrm{Na}$ arquitetura, por exemplo, a crença no potencial da arquitetura de contribuir às transformações em curso através do espaço construído, que vinha sendo experimentada pelos arquitetos em projetos privados, teve, com esse plano, a possibilidade de ser testada e desenvolvida, resultando em projetos inovadores enquanto à forma, técnica e programa. Há um expressivo conjunto de projetos contratados por esse plano com soluções espaciais inéditas de explícita valorização dos espaços coletivos, com soluções construtivas inovadoras que repercutiram no avanço da engenharia e que se dispuseram a repensar a relação entre a arquitetura e a cidade.

\subsection{Levantamento documental}

A diversidade de documentos, a disparidade de formação e o envolvimento dos pesquisadores exigiram a sistematização da informação da forma mais simples, rápida e eficiente. A partir do levantamento das fichas dos vários órgãos de preservação, de instituições responsáveis por levantamentos, DOCOMOMO por exemplo, de acervos públicos e frente às especificidades da nossa pesquisa, foi elaborada uma ficha que atendesse de modo mais amplo às variadas demandas - de processos administrativos a levantamentos de campo. O preenchimento da ficha, portanto, muitas vezes não seria completo. Mesmo assim, visando à otimização e padronização das informações, optou-se por um modelo que contemplasse a diversidade de acervos, ainda que, numa primeira etapa, muitos campos ficassem vazios (Figura 3).

A pesquisa concentrou-se no levantamento de seis acervos públicos: Ipesp, CPOS; SEF, FDE; biblioteca da FAU-USP e Secretaria da Agricultura e Abastecimento. Teve o apoio de pesquisas realizadas anteriormente pelos pesquisadores envolvidos em acervos dos arquitetos Oswaldo Arthur Bratke, Fábio Penteado, Joaquim Guedes, João Vilanova Artigas, Paulo Mendes da Rocha e Carlos Millan. 
FIGURA 3

Ficha-modelo do inventário.

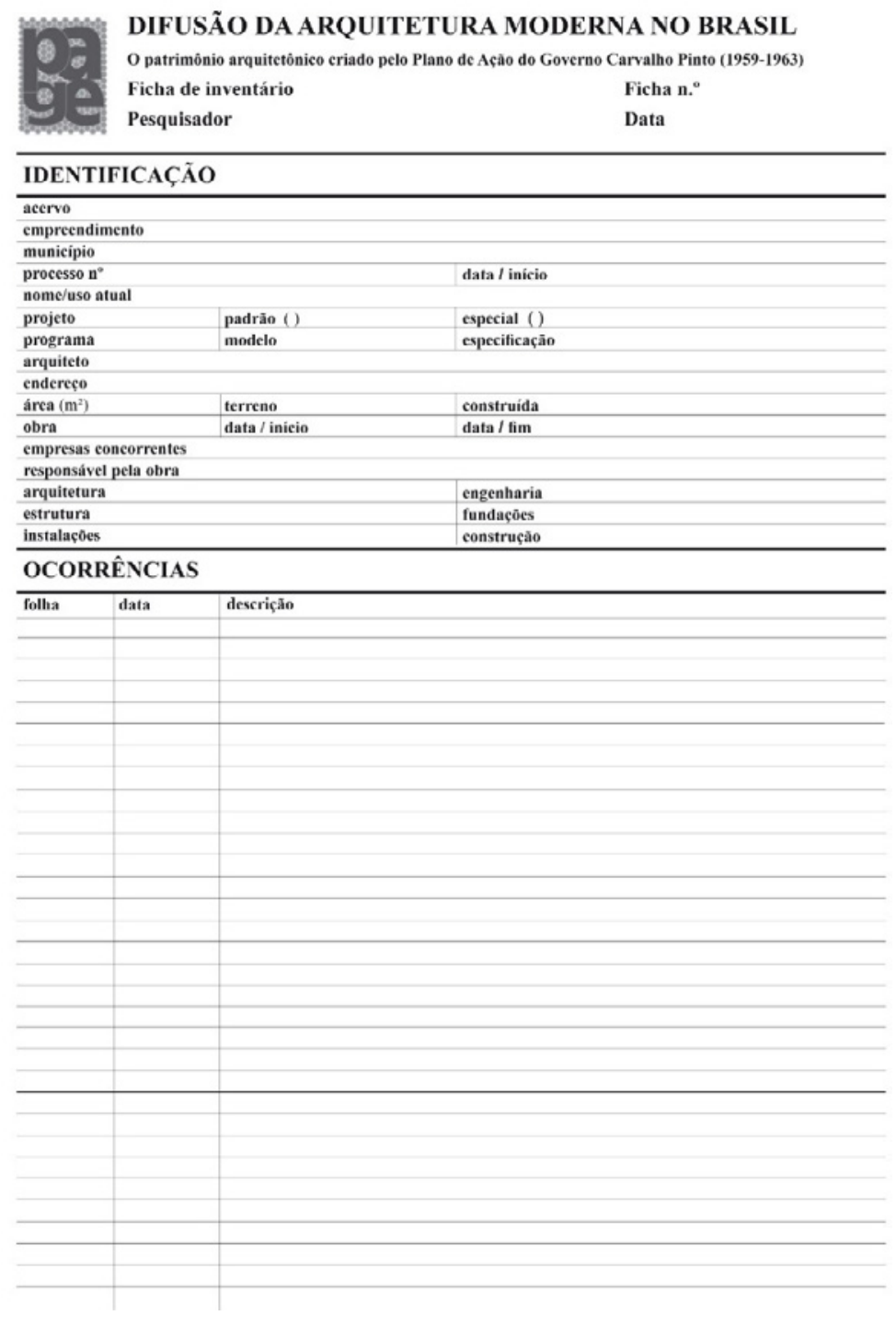

\subsubsection{Acervos}

Instituto da Previdência do Estado de São Paulo - Ipesp

O Ipesp foi um dos grandes financiadores das obras do PAGE e teve papel fundamental na viabilização da contratação de projetos com profissionais fora do serviço público. Embora esse recurso tenha sido utilizado na gestão anterior do governador Jânio Quadros, não foi com o mesmo destaque. O 
acervo documental do Ipesp é constituído de processos administrativos, sendo os relativos ao Plano de Ação uma parcela do Arquivo Geral, que é subordinado à Diretoria de Matérias e Serviços e ao Departamento de Atividades Complementares do Ipesp, localizado, à época do nosso levantamento, na Rua Catumbi, no bairro do Belenzinho. Os edifícios públicos do PAGE pertenciam à Comissão e Gestão de Imóveis (CGI), atrelados à Secretaria da Fazenda, que por sua vez, alugava ou cedia-os às Secretarias e Municípios.

$\mathrm{O}$ arquivo estava organizado, limpo e arejado; os processos em geral, estavam em bom estado de conservação ainda que alguns apresentassem intervenções inadequadas como o uso de fitas adesivas para reparos, grampos, folhas e imagens soltas. As raras cópias heliográficas de arquitetura encontradas em processo estavam em degradação (manchadas, quebradiças), portanto facilmente de serem mais danificadas (Figura 4).

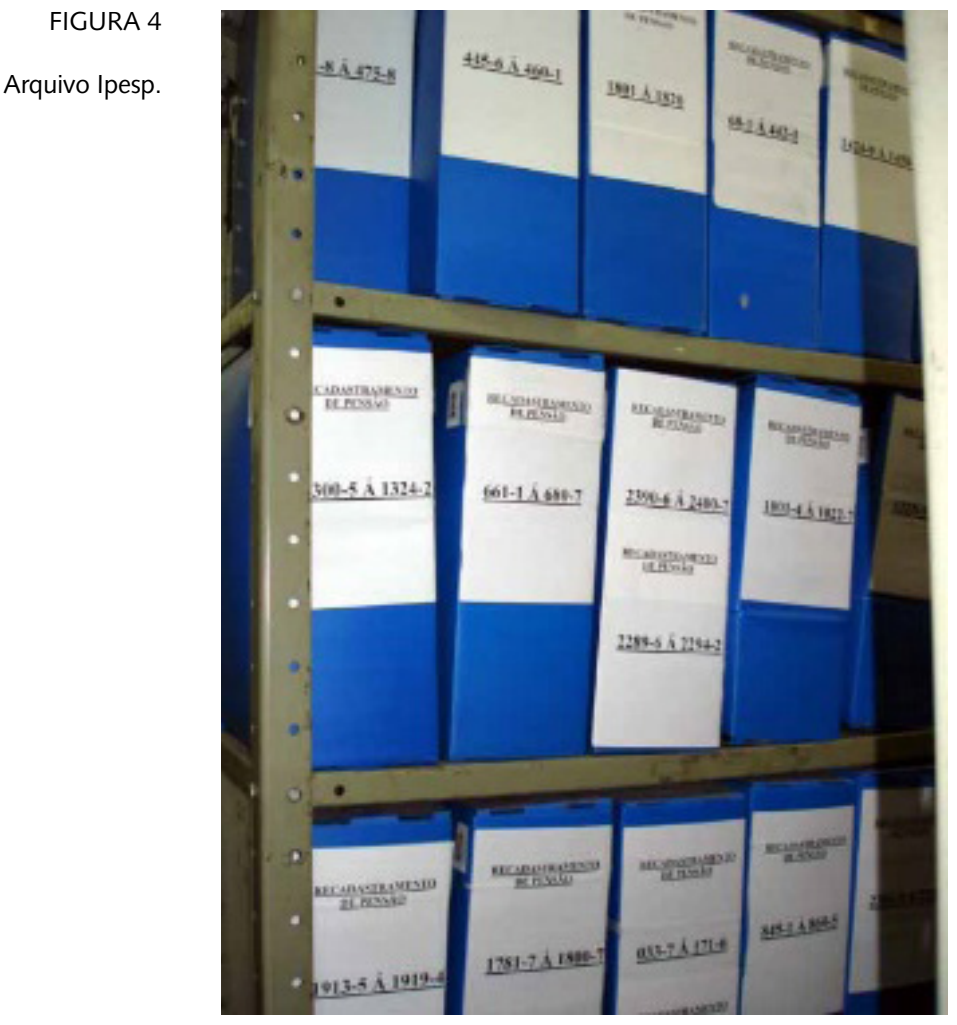


Os processos da CGI estavam organizados em ordem alfabética por cidade e dizem respeito aos trâmites da contratação da obra e da doação do terreno à obra executada. Os processos de obra seguiam, de modo geral, o seguinte fluxograma: 1- protocolo do pedido: construção da obra; 2apresentação da documentação do terreno; 3- vistoria do terreno; 4- aceite e transferência de propriedade para o Ipesp e encaminhamento para obra; 5- edital de concorrência para a construção da obra; 6- contratação da empresa vencedora; 7- execução e pagamentos; 8- locação da obra para a secretaria afim. Nesses processos, para além da contratação do arquiteto, são poucas as informações arquitetônicas. Peças gráficas dos projetos são raras e mesmo fotos de fiscalização das obras comparecem de forma assimétrica nos projetos.

Foram encontrados muitos processos em aberto, porque o Ipesp, à época do levantamento, passava por uma reformulação devido à criação de um novo órgão para a previdência do estado, SPPREVI, que atribuía ao Ipesp uma nova estrutura funcional incompatível com a guarda desse acervo. A verificação dos procedimentos pendentes na documentação desses processos exigiu a sua transferência para Secretaria da Fazenda do Governo do Estado, onde devem permanecer definitivamente e sem acesso a pesquisadores. Foi talvez a última oportunidade de pesquisadores consultarem esses documentos.

O levantamento do acervo do Ipesp teve o seguinte procedimento por parte dos pesquisadores: retirada dos processos das prateleiras (segundo ordem alfabética por município); triagem, separando para inventário apenas os processos pertencentes ao período recorte da pesquisa (1959-1963) e que, pertencendo ao período, tivessem recebido projeto arquitetônico desenvolvido por arquiteto não funcionário do governo. Tais processos foram denominados de "autorais"; análise do processo, preenchimento da ficha de inventário e definição daquilo que deveria ser capturado em imagem; captura das imagens: fotografia e/ou scanner; transferência das imagens para o notebook, separação em pastas e junção de fichas e imagens em única pasta nomeada com o número do processo; organização e arquivo dos processos analisados. As pastas e fichas foram nomeadas segundo os seguintes campos: No do processo_/ ano_/ município /_tipologia /_pesquisador. Ex: 12345-61_Avaré_GrupoEscolar_Pesquisador. As imagens foram colocadas 
na mesma pasta que as fichas. Foram pesquisados 428 municípios, totalizando 1177 processos, dos quais 429 foram inventariados (por estarem dentro do período recorte do projeto) e desses, 305 contaram com projetos elaborados por arquitetos não funcionais.

\section{Arquivo da Companhia Paulista de Serviços e Obras (CPOS)}

Esta autarquia, localizada à rua Tangará, 70, Vila Mariana, é responsável pela guarda da documentação gráfica dos projetos e das obras contratadas pelo governo do Estado de São Paulo. A CPOS é herdeira do acervo do Departamento de Obras Públicas (DOP), órgão criado no final do século XIX para concepção, execução e administração dos projetos e obras desenvolvidos pelo Estado de São Paulo. Trata-se de um acervo de trabalho que reúne todos os documentos gráficos dessas obras, que, a cada nova intervenção nesses prédios, permite que a documentação arquivada possa ser solicitada, o que não lhe retira o seu caráter histórico. Entretanto, esse acervo foi terceirizado a partir deste século e tramitou por várias empresas fora do município de São Paulo, dificultando seu acesso. Esse tem sido o mais difícil dentre os acervos até então levantados, apesar das insistentes solicitações dos diretores do IAU-São Carlos e da FAU-USP. Esse acervo, já consultado em outras oportunidades por diferentes pesquisadores envolvidos nesta pesquisa, tem sido, desde sua terceirização, cada vez mais desestruturado, seja nas condições de seu arquivamento, seja na sua identificação, dificultando sobremaneira a pesquisa. A terceirização não considerou a importância histórica dessa documentação. Trata-se do acervo mais importante da arquitetura, da engenharia e da construção civil do Estado de São Paulo. Os projetos são arquivados em contêiners, sem qualquer cuidado quanto a sua conservação.

Frente às dificuldades de acesso e à relevância da documentação, a pesquisa na CPOS se deu a partir dos projetos identificados pelo levantamento do IPESP e por uma antiga listagem da própria CPOS conseguida pelos pesquisadores anteriormente à terceirização. Nosso contato sempre foi com a CPOS, nunca tivemos acesso aos depósitos de projeto, apesar de termos sugerido ir até o local onde estariam armazenados e desenvolver o levantamento de maneira intensiva. Os projetos eram, então, solicitados à CPOS que encaminhava o pedido à empresa e esta por sua 
vez os trazia até a sede da CPOS. Essa tramitação demorava em média dois meses, e não raro o material que chegava não correspondia ao que fora solicitado. Os mesmos só podiam ser analisados na CPOS, em local não muito adequado à consulta.

Outro entrave ao desenvolvimento da pesquisa nesse acervo foi o alto custo cobrado pelas cópias dos desenhos. Há que se registrar que o preço era muito superior ao do mercado. Mesmo com as justificativas dos diretores das faculdades envolvidas, esclarecendo tratar-se de uma pesquisa acadêmica de uma universidade pública, subsidiada com verba pública, não foi possível agilizar o processo. Foi o maior impasse administrado pela pesquisa. Foram feitas várias tentativas de acordo em algumas reuniões realizadas com os diretores da CPOS e responsáveis pelo acervo, mas nenhuma prosperou, sobretudo porque houve muitas mudanças de gestão na CPOS, e a cada novo superintendente que assumia como diretor, era preciso reiterar os pedidos.

Em julho de 2013, fomos informados de que o acervo voltaria à CPOS, o que de fato só aconteceu em fevereiro de 2015. Graças à boa vontade do responsável pelo acervo, conseguimos consultá-lo, ainda que de forma muito precária. $\mathrm{O}$ material não estava catalogado, a busca se dava por meio de tentativa e erro, com base numa aproximação da numeração que tínhamos como referência, a partir da qual buscava-se algumas correspondências entre sequências de codificação, tipologias e datas. Encontramos muitas embalagens com excesso de material, exigindo desmontá-las para ter acesso aos desenhos, muitos deles danificados. Com pouco tempo e condições precárias de espaço, ainda assim foi possível a verificação de 130 tubos de projetos, com mais de mil pranchas, dos quais 59 referentes ao período do Plano de Ação. Um resultado muito aquém do que de fato deve existir, pois o acervo é constituído de mais de 10 mil tubos.

\section{Superintendência de Espaço Físico da USP (SEF-USP)}

A Superintendência de Espaço Físico da USP (SEF-USP) é responsável pela guarda da documentação gráfica relativa à Cidade Universitária Armando Salles de Oliveira (CUASO), cujo acervo encontra-se no prédio da reitoria, em condições minimamente adequadas, cuja situação detalhada é tema do artigo de Sabrina Fontenelle, também publicado nesta edição. 
A SEF-USP é herdeira do FCCUASO, fundo especialmente criado pelo PAGE para a construção da cidade universitária, portanto, aí deveriam estar todos os documentos relativos aos projetos e obras contratados nesse período. Entretanto, não é o que foi verificado pela pesquisa. A catalogação é feita pelo edifício, mas há um número muito maior de desenhos do que os catalogados. Nesta etapa beneficiamo-nos do levantamento realizado pelo Centro de Preservação Cultural da USP (CPC-USP) para os bens tombados e/ou em processo de tombamento que registrou 4.000 desenhos, já tendo digitalizado 70 pranchas, que nos foram disponibilizados à consulta. A partir desse levantamento demos continuidade ao inventário, consultando os projetos dos bens não tombados, contratados e/ou realizados entre 1959 e 1963, cujas cópias foram feitas pela própria SEF.

\section{Secretaria da Agricultura e do Abastecimento de São Paulo}

A Secretaria da Agricultura e do Abastecimento tem a função gerencial e administrativa de prestação técnica aos assuntos que envolvem as questões da agricultura no Estado de São Paulo. Criada com a República instaurada em 1889, tinha entre seus departamentos o de Viação e Obras Públicas, que em 1927 tornou-se uma secretaria independente. Mas a Secretaria da Agricultura seguiu responsável por muitas obras relativas ao desenvolvimento agrícola do estado, como as cooperativas, as casas de lavoura e as obras para o armazenamento e distribuição dos produtos, subordinadas ao Departamento de Engenharia e Mecânica da Agricultura (DEMA). À época do levantamento, a Secretaria localizava-se no Jabaquara e a partir de dezembro de 2014 foi transferida para o centro da Cidade, no edifício do antigo Hotel Esplanada, na Praça Ramos de Azevedo.

Sendo um dos objetivos do PAGE o desenvolvimento do interior do estado de São Paulo, que tinha a agricultura como a mais forte atividade econômica, foi proposto equipar e construir 25 escolas de iniciação agrícola, 308 casas da lavoura, 29 sedes de delegacias agrícolas e 16 sedes de extensão agrícola; além de equipar, ampliar ou reformar 8 fazendas experimentais, 5 postos de criação, 9 recintos de exposição, 18 estações de pesca, o Instituto Agronômico de Campinas e suas 14 fazendas experimentais e outros centros de pesquisa e experimentação agrícola e de zootecnia. A obra de maior visibilidade sem dúvida foi o Centro Estadual de Abastecimento (Ceasa), na cidade de São Paulo. 
O DEMA, a partir de 1961, com a contratação de novos arquitetos passou a incorporar nos seus projetos nova linguagem arquitetônica. Como da CPOS e SEF, é também um arquivo de trabalho e pouco organizado. Há livros de registro onde estão anotados os projetos por ordem de entrada no órgão, e não pela data de execução, e muitos documentos não tinham qualquer identificação. Houve inicialmente um trabalho de organização do acervo para a posterior consulta. Foram analisados 600 projetos e 453 foram digitalizados.

\section{Secretaria da Saúde - setor de projetos}

Sabemos, pelos relatórios anuais do PAGE, que houve considerável investimento na área da Saúde, especialmente na construção de postos de saúde e na adaptação de hospitais frente à superação de algumas doenças, como a tuberculose, por exemplo, e às novas orientações no campo da medicina, como os hospitais psiquiátricos. Muitos desses hospitais foram adaptados a hospitais gerais, conforme depoimento de Domingos Theodoro de Azevedo.

Contudo, segundo o arquiteto Adhemar Dizioli Fernandes, diretor técnico do Departamento -Grupo Técnico de Edificações (GTE), a Secretaria da Saúde até o início dos anos 1980 não tinha equipe de projetos e obras. Os centros de saúde e hospitais eram executados pelo DOP. Apenas durante a década de 1980 organizou-se a assessoria de obras da SES, que deu origem ao atual GTE e, portanto, a documentação do PAGE não está sob a guarda da SES, mas sim da CPOS. Como na CPOS, o levantamento de projetos foi muito problemático, a investigação dos empreendimentos da Saúde foi a que teve menor expressão na pesquisa.

\section{Fundação para o Desenvolvimento da Educação (FDE)}

Criada em 1987, no âmbito da Secretaria de Estado da Educação, a FDE é herdeira do FECE - fundo especialmente criado pelo PAGE para a construção de escolas e tem em seu arquivo cópias de quase todos os projetos contratados pelo PAGE. Os originais continuam na CPOS, ou pelo menos, deveriam estar lá. $\mathrm{Na}$ impossibilidade de acesso por parte dos pesquisadores aos originais da CPOS, como anteriormente explicado, a pesquisa buscou cobrir essa produção - a de maior investimento 
do PAGE - no arquivo do FDE. Entretanto, a consulta não foi totalmente aberta, havendo controle sobre o material disponibilizado. Os códigos de acesso às plantas não foram liberados, dificultando sua identificação. Foi fornecido um CD com os desenhos digitalizados, também sem um controle que facilitasse a pesquisa.

\section{Instituto dos Arquitetos do Brasil-SP (IAB-SP)}

A documentação do IAB - as atas - sofreu uma perda decorrente de uma enchente, mas foi possível recuperar registros de reuniões que esclareceram algumas pendências da pesquisa.

\section{Biblioteca FAU-USP}

$\mathrm{O}$ acervo de projetos da biblioteca da FAU-USP é composto sobretudo por coleções de desenhos de arquitetos, sendo um dos mais importantes da América Latina. Integram esse acervo coleções de arquitetos que participaram do PAGE: João Vilanova Artigas, Eduardo Kneese de Mello, Oswaldo Bratke, Eduardo Corona, Carlos Millan e Joaquim Guedes.

\subsection{Levantamento de Campo}

Considerando os objetivos do projeto de pesquisa, havia uma grande expectativa nessa atividade, que permitiria a confrontação entre projeto e espaço construído. Entretanto, a morosidade no levantamento dos projetos e a indisponibilidade de muitos deles acabou por comprometer o seu desenvolvimento tal como previsto, ou seja, o estudo do projeto antes da vista à obra.

As visitas técnicas, além do reconhecimento do espaço, restringiram-se em muitos casos à avaliação do estado de conservação e nas alterações realizadas no percurso de 50 anos, como puxados, ampliações para atender o programa e mesmo mudança de uso.

Constatou-se um total desconhecimento sobre as construções dessas obras e o vínculo com o Plano de Governo, embora muitas ainda mantenham de modo muito visível a placa de bronze do Plano de Ação. Foram visitados mais de 70 municípios, num total de 300 obras. Algumas delas têm em seus arquivos algum documento de projeto. 


\section{RESULTADOS}

Os dados coletados pelos levantamentos realizados, bibliográfico, arquivístico e de campo, foram analisados e sintetizados em planilhas e listagens no sentido de, primeiramente, ordenar as informações: por município, por tipologia, por autor de projeto etc.

A pesquisa identificou que pelo menos 275 municípios receberam obras do PAGE, a saber: Águas de São Pedro, Agudos, Alto Alegre, Álvares Machado, Alvinlândia, Americana, Amparo, Andradina, Aparecida, Apiaí, Araçatuba, Araras, Artur Nogueira, Arujá, Assis, Atibaia, Auriflama, Avaré, Barretos, Barueri, Bauru, Bebedouro, Bento de Abreu, Bernardino de Campos, Bilac, Birigui, Bocaina, Botucatu, Brodowisk, Brotas, Buri, Buritama, Buritizal, Cabrália Paulista, Caçapava, Cachoeira Paulista, Cafelândia, Caieras, Cajobi, Cajuru, Camoinas, Campos do Jordão, Candido Mota, Caraguatatuba, Cedral, Cerquilho, Charqueada, Chavantes, Colina, Conchal, Cosmorama, Cunha, Dois Córregos, Dracena, Duartina, Estrela D’Oeste, Flórida Paulista, Franca, Franco da Rocha, Gália, Graça, General Salgado, Guapiaçú, Guará, Guarujá, Guarulhos, Herculândia, Ibiúna, Icem, Iepe, Igarapava, Indaiatuba, Núbia Paulista, Ipauçu, Iracemápolis, Irapuru, Itaberá, Itanhaém, Itapecerica da Serra, Itapetininga, Itapeva, Itapira, Itaporanga, Itaquaquecetuba, Itararé, Itariri, Itu, Ituverava, Jaboticabal, Jacareí, Jaguariúna, Júlio Mesquita, Jundiaí, Junqueirópolis, Laranjal Paulista, Lavínia, Leme, Lençóis Paulista, Limeira, Lorena, Lucélia, Macaubal, Marabá Paulista, Maracaí, Marília, Mauá, Miracatu, Mirante do Paranapanema, Mirassol, Mogi das Cruzes, Mogi Mirim, Mogi-Guaçu, Monte Alto, Monte Aprazível, Monte Azul Paulista, Monte Castelo, Muritinga do Sul, Nova Granada, Novo Horizonte, Ocauçú, Óleo, Orlândia, Oscar Bressane, Oswaldo Cruz, Ourinhos, Pacaembu, Paraguaçu Paulista, Parapuã, Patrocínio Paulista, Paulo de Faria, Pedereira, Pereira Barreto, Peruíbe, Pindorama, Piquete, Piracicaba, Pirajuí, Pirapozinho, Pirassununga, Pitangueiras, Pompéia, Pontal, Porongaba, Porto Feliz, Presidente Bernardes, Presidente Prudente, Presidente Wenceslau, Promissão, Queluz, Quintana, Rancharia, Ribeirão dos Índios, Ribeirão Pires, Ribeirão Preto, Rio Claro, Rio das Pedras, Sagres, Salesópolis, Salto Grande, Santa Branca, Santa Cruz do Rio Pardo, Santa Isabel, Santa Mercedes, Santa Rosa do Viterbo, Santo 
Anastácio, Santo André, Santo Antonio da Posse, Santos, São Bernardo do Sampo, São Caetano do Sul, São Carlos, São Joaquim da Barra, São José do Rio Preto, São José dos Campos, São Paulo, São Roque, São Simão, Sertãozinho, Sete Barras, Silveiras, Socorro, Sorocaba, Sud Mennúci, Suzano, Tanabi, Taquaritinga, Taubaté, Tupã, Tupi Paulista, Ubatuba, Valinhos, Vargem Grande do Sul, Vera Cruz, Vinhedo, Votuporanga.

Desses, a pesquisa levantou empreendimentos em 188 municípios. Dentre os 652 imóveis levantados nos vários acervos pela equipe de pesquisadores, 511 foram identificados como obras do PAGE, dos quais 163 foram selecionados para estudo, listados a seguir, segundo a área administrativa, tipologia e localização (Figuras 5, 6 e 7).

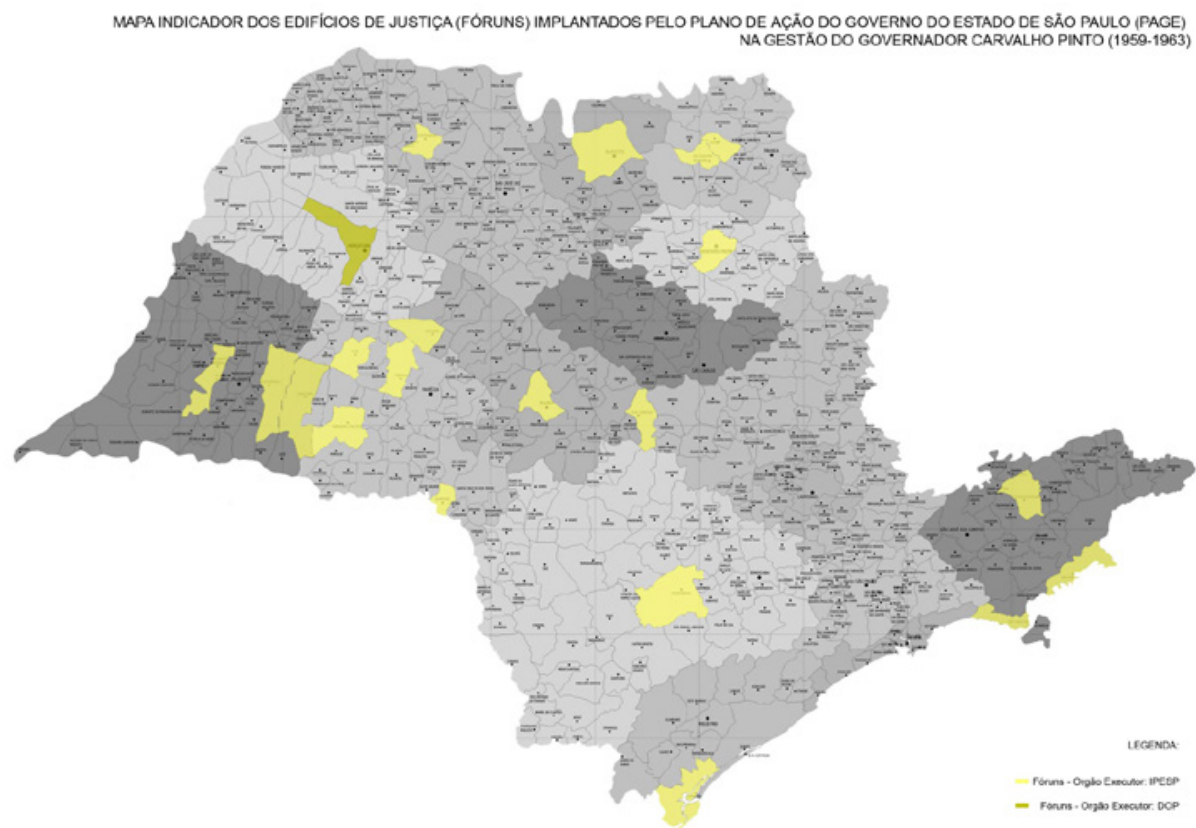


FIGURA 6

Localização dos grupos escolares e ginásio do estado.

FIGURA 7

Localização dos edifícios da Saúde.

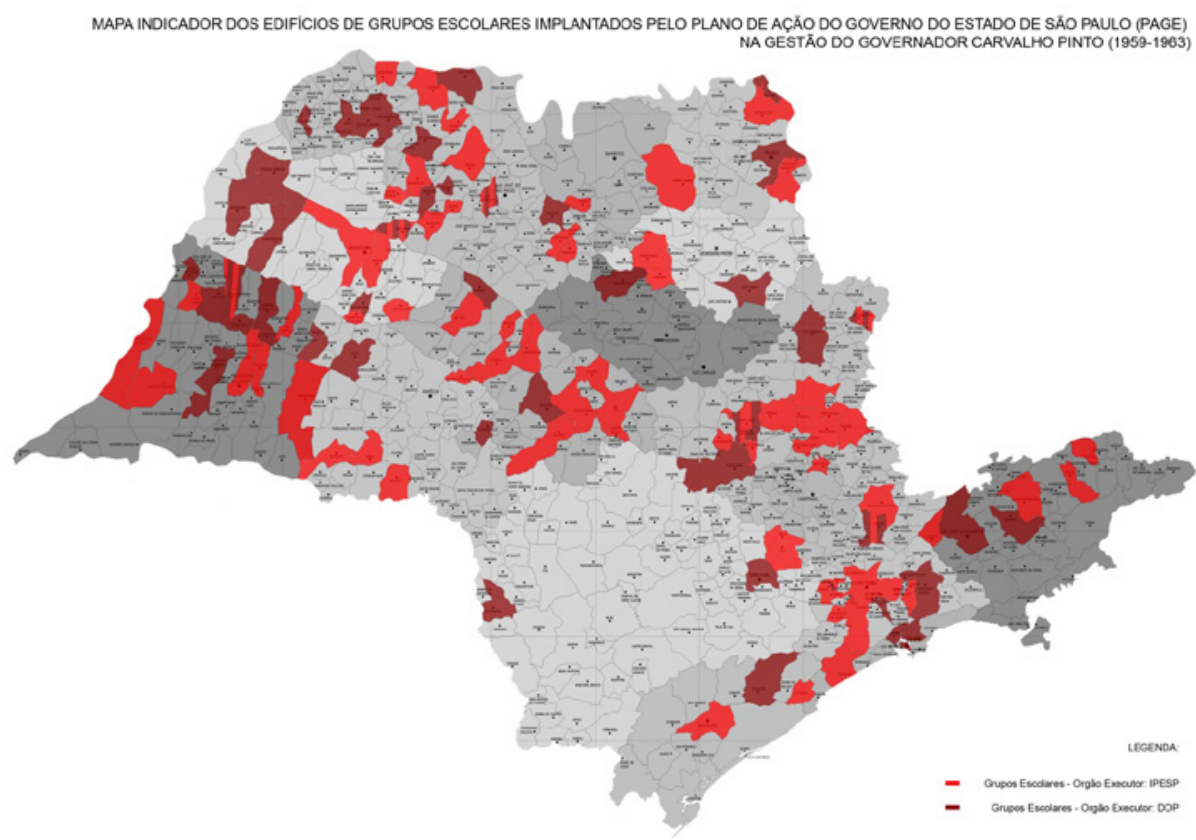

MAPA INDICADOR DOS EDIFICIOS DE SAUDE (POSTOS E UNID. SANIT.) IMPLANTADOS PELO PLANO DE ACÁO DO GOVERNO DO ESTADO DE SÃO PAULO (PAGE)

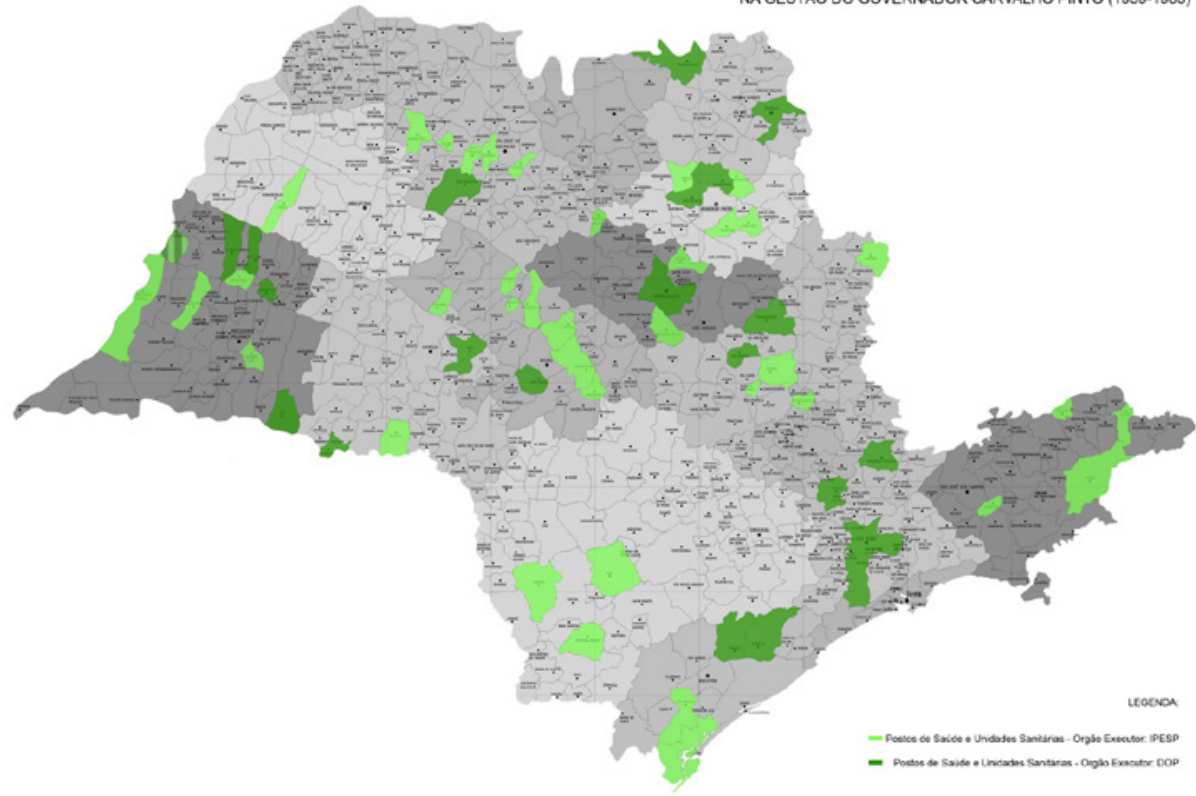


Agricultura: 17 edifícios, dos quais uma Delegacia Regional Agrícola, em Franca; e 16 casas de lavoura, nos municípios de Bocaina, Duartina, Getulina, Guarei, Irapuru, Itapira, Itu, Jaboticabal, Jaguariúna, Paulo de Faria, Promissão, Rincão, Rio Claro, São Carlos, Tanabi, Tiête.

Judiciário: 28 edifícios, dos quais três delegacias de polícia em Adamantina, Irapuru, Jaguariúna; e 25 fóruns, nos municípios de Amparo, Araras, Avaré, Caconde, Duartina, Itapeva, Itapira, Leme, Lucélia, Mogi Mirim, Orlândia, Paulo de Faria, Pedregulho, Piedade, Piracicaba, Promissão, Ribeirão Preto, Santa Isabel, Santa Rosa do Viterbo, São Carlos, São Simão, Socorro, Tanabi e Tiête.

Educação: 62 edifícios escolares, entre grupos, ginásios, instituto de educação e faculdade, segundo a distribuição: 2 em Adamantina; 1 em Amparo; 3 em Araçatuba; 4 em Araraquara; 3 em Barretos, 1 em Batatais; 1 em Bocaina; 1 em Itanhaém; 3 em Campinas; 1 em Duartina; 4 em Franca; 1 em Iguape; 2 em Irapuru; 3 em Itapira; 1 em Itu; 4 em Jaboticabal; 2 em Jaguariúna; 1 em Lucélia; 6 em Marília; 3 em Mogi Mirim; 1 em Paulínia; 1 em Paulo de Faria; 2 em Piracicaba; 4 em Rio Claro; 1 em Santa Isabel; 1 em Santa Rosa do Viterbo; 2 em São Carlos; 1 em São Paulo; 1 em São Simão; 1 em Tanabi.

Foram redesenhados 45 projetos, sendo 11 com maquetes eletrônicas: Departamento de História e Geografia/FFLCH-USP; FAU-USP; Fóruns de Amparo; Araras; Itapira; Promissão; Grupo Escolar de Presidente Prudente; Ginásios de Estado em Itanhaém, Guarulhos, Campinas, São José dos Campos e Marília. E quatro com maquetes físicas: Fóruns de Araras e Avaré; do Ginásio de Itanhaém e da FAU-USP.

A partir desses estudos foi possível sugerir uma primeira classificação dos projetos pelas suas características arquitetônicas, agrupadas em quatro categorias: 1- volume único, com um ou mais níveis, e um espaço central articulador de todo o conjunto; 2 - blocos independentes separados pela função, interligados por passadiços cobertos; 3- sistema pavilhonar, com distribuição linear das funções com diagramas em forma de "L" " $U$ ", "H”ou “T", entre outras variantes; 4- soluções excepcionais, inovadoras e que não se encaixam nas outras categorias.

Os levantamentos identificaram a participação de cerca de 160 arquitetos nas obras do PAGE: 
Abelardo de Souza, Abelardo Gomes de Abreu, Abelardo Reidy de Souza, Abrahão Sanovicz, Adolfo Ortemblat Filho, Adolpho Rubio Morales, Afonso Eduardo Reidy, Alberto David, Moreira Andrade, Alberto Rubens Botti, Alfredo Paesani, Ari de Queiroz Barros, Ariosto Mila, Arnaldo Furquim Paolielo, Arnaldo Grostein, Arthur Fajardo Netto, Ayako Nishikawa, Bernardo José Castelo Branco, Carlos Barja Millan, Candido Malta Campos Filho, Carlos Alberto Cerqueira Lemos, Carlos Benvenuto Fongaro, Carlos Cascaldi, Carlos Gomes e Cardim, Dácio Ottoni, Dante de Souza Pereira Autuori, Dario Monteano, David Araujo Benedito Ottoni, Décio Tozzi, Djalma Macedo Soares, Dora Aksenfeld, Eduardo Corona, Eduardo Kneese de Mello, Elisário Cunha Bahiana, Eneas Fernandes de Carvalho, Ernesto Varga Cardoso, Fábio Arantes S. Aquino Leme, Fábio Eduardo Kok de Sá Moreira, Fabio Moura Penteado, Feitor Ferreira de Souza, Fernando Augusto Senna Arantes, Francisco A. Saraiva Farnniele, Francisco Petracco, Galjaro Chanpaglia, Giancarlo Gasperini, Giancarlo Palanti, Gilberto Junqueira Caldas, Gilberto Othoniel Toni, Gregório Zolko, Hamilton M. de Campos, Heinz Toland Weder, Heitor Ferreira de Souza, Hélio de Queiroz Duarte, Hélio Pasta, Hélio Penteado, Helmut Hein, Henrique Signore Sadocco, Hernani Russo, Hirohiko Sawao, Hiroko Kawauchi, Hoover Américo Sampaio, Icaro de Castro Mello, Israel Galman, Jacob Maurício Ruchti, Jaguanhara de Toledo Ramos, Jon Andoni Vergareche Maitrejean, Janusz Wlodzimierr Wojdyslawski, Jarbas B. Karman, Jerônimo Esteves Bonilha, João Batista Alves Xavier, João Carlos Bross, João Clodomiro de Abreu, João Francisco Portilho de Andrade, João Marino, João Batista Vilanova Artigas, João Walter Toscano, João Xavier, Joaquim Guedes Sobrinho, Joel Ramalho Júnior, Jorge Nomura, Jorge Wilheim, Jorge Zalszupin, José Caetano de Mello Filho, José Luiz Fleury de Oliveira, José Maria Gandolfo, José Maria Monfort, José Pinto, José Roberto Martins, Jose Silvestre Viana Egreca, Julio José Franco Neves, Júlio Roberto Katinsky, Kurt Holland, Leo Ribeiro de Moraes, Lucio Grinover, Lucjan Korngold, Luis Fernandes A. Moraes, Luis Porto Netto, Luiz Contrucci, Luiz Forte Neto, Luiz Pessoa Ortiz, Majer Botkowski, Marc Rubin, Marcelo Accioly Fralli, Marcos Monlevard Tomanik, Mário Simons Barbosa, Mario Zocchio, Maurício Nogueira Lima, Maurício Tuck Schneider, Miranda Martinelli Magnolli, Nelson A.M. Morse, Nes- 
tor Linderberg, Ney de Carvalho Marcondes, Oscar Panzoldo, Oswaldo Arthur Bratke, Oswaldo Correa Gonçalves, Otacilio Rodrigues Lima, Paulo Eduardo Martins de Oliveira, Paulo Floriano de Toledo, Paulo Renan, Paulo Renan Namede, Pedro Paulo de Melo Saraiva, Plínio Crocce, Renato Alessandri, Ricardo Sievers, Rita Olmo, Roberto Bratke, Roberto Cláudio dos Santos Aflalo, Roberto Gabriel Maurício Gontier, Roberto José Goulart Tibau, Roberto Monteiro, Rodolpho Ortemblad Filho, Rodrigues de Lima, Roger Henri Wailer, Roger Zmekhol, Romeu Thomé da Silva, Rodolpho Ortemblad Filho, Ronaldo Dumani, Rino Levi, Rosa Grená Kliass, Rubens G. Carneiro Vianna, Rubens Cezar Madureira Cardieri, Rubens Monteiro, Salvador Candia, Samuel Spieguel, Sérgio Teperman, Setsuo Kamada, Sliógenes Vieira Negrão, Sliomar Selter, Teodoro Castro Mello, Ubaldo Carpigiani, Ubirajara Gonçalves Gilioli, Ubirajara Mota Lima Ribeiro, Victor Reif, Walter S. Kneese, Wlademir Kliass, Zenon Lotufo, Zilah Terezinha Castrucci Tambasco.

\section{CONSIDERAÇÕES FINAIS}

O levantamento realizado identificou uma parcela da documentação relativa ao Plano de Ação do Governo Carvalho Pinto, cuja dispersão em diversos arquivos desvendou uma rede ampla e diversificada de documentos ainda a ser perscrutada. Se a difusão da arquitetura moderna em São Paulo, a partir do final dos anos 1950, foi a motivação inicial da pesquisa, tendo em vista que algumas de suas obras eram paradigmáticas da arquitetura paulista, o complexo acervo que se descortinou com o andamento dos trabalhos nos trouxe muitas outras questões.

Primeiramente esta pesquisa corrobora o potencial da arquitetura e dos registros de seu processo - dos desenhos à obra construída - à investigação histórica, para além daqueles aspectos inerentes ao próprio campo disciplinar, como programa, técnicas construtivas e estética. Os desenhos, os objetos arquitetônicos e a relação entre eles, embora parte de um único processo, mostram que cada uma das etapas pode constituir uma frente de pesquisa per si. Segundo Dal Co (2013, p. 9), "desenho de arquitetura é de natureza transitória, mas estável; é um instrumento e, como tal, é apenas uma alusão, mais do que uma previsão, daquilo que não é visível e perceptível aos nossos sentidos". 
Se é possível verificar que o reconhecimento de edifícios como patrimônio cultural vem, muito lentamente, sendo compreendido pela sociedade, o mesmo não é possível afirmar sobre os desenhos. Exceção feita à Biblioteca da FAU-USP, nenhum dos arquivos de desenhos levantado neste trabalho tem a dimensão de sua condição histórica, conforme expusemos. Uma proposta nessa direção se faz absolutamente necessária.

Do ponto de vista da expansão da arquitetura moderna - a premissa fundante desta pesquisa - o resultado da investigação, ainda que parcial, é inconteste. $\mathrm{O}$ grande número de obras produzidas segundo os princípios da arquitetura moderna comprova a assimilação dessa corrente nos quatro cantos do estado. Entretanto, não se trata de uma frente única, muito menos homogênea. Nesse conjunto de projetos foram encontradas obras das mais variadas filiações estilísticas, acadêmicas e neocoloniais. Um dado relevante que este inventário descortina é a diversidade dessa produção, que mesmo compartilhando princípios modernos, nem sempre da mesma linhagem, apresentam uma grande variedade de resultados.

A divulgação dos princípios modernos da arquitetura pelo PAGE não se restringiu ao magnífico conjunto de obras que vimos comentando, mas contribuiu para a modernização das instituições públicas e, consequentemente, para os projetos nelas produzidos, conforme depoimento de Whitaker (2007):

O DOP trabalhava com procedimentos antigos, tinha setores separados para arquitetura, hidráulica, elétrica etc. Quando entrava um projeto cada setor desenvolvia isoladamente sua tarefa e ficava circulando entre eles separadamente, sem noção de conjunto, perdendo muito tempo no projeto. Então veio a ideia, por influência do padre Lebret, que tinha ideias de interdisciplinaridade, do DOP fazer ateliês para desenvolver o trabalho completo. Quer dizer, nos ateliês, que tinham outro nome na época, tinha o arquiteto, o hidráulico, todos os técnicos das diversas fases da obra. Eles pegavam o projeto e tinham que resolver integralmente.

Assim, a relação das obras paradigmáticas da história da arquitetura paulista com o PAGE traz outra leitura do seu papel no contexto nacional. Não se trata de obras isoladas, mas incorporam uma proposta muito mais 
ampla que exigiu dos arquitetos uma pronta resposta, como revela o depoimento de Paulo Camargo e Almeida, diretor do FCRCUASO:

(...) em reuniões semanais, com a presença do diretor da FAU Anhaia Mello, do reitor Ulhoa Cintra foi conseguida a unidade necessária ao planejamento, que transformará, estamos convictos, a cidade Universitária Armando Salles de Oliveira na maior demonstração da cultura arquitetônica dos tempos atuais, sem os formalismos e os luxos condenáveis que vimos percebendo e sentindo nas realizações da arquitetura mundial contemporânea.

Contemporâneas à construção de Brasília, as obras do PAGE podem ser entendidas como uma resposta paulista ao predomínio da arquitetura carioca nessa aventura nacional. $\mathrm{O}$ envolvimento de centenas de profissionais numa mesma proposta política, produzindo obras públicas, estimula a troca de ideias, fortalece princípios e propicia inovações. Não por acaso esse período consolida o movimento identificado como Escola Paulista.

O discurso muito presente na historiografia da arquitetura paulista de que a arquitetura moderna em São Paulo teria ficado à mercê do mercado imobiliário, dada a ausência de uma demanda de obras públicas, não procede frente aos levantamentos aqui apresentados.

Para a arquitetura, o PAGE é um marco referencial e a compreensão histórica do próprio Plano trouxe muitas indagações nas mais variadas áreas do conhecimento, abrindo infinitos temas a serem perscrutados a partir de sua documentação: relações de trabalho, o campo profissional do arquiteto, a arquitetura autoral e produção pública de projetos, o desenvolvimento tecnológico, a qualidade da construção, para não dizer de uma revisão historiográfica que se faz absolutamente necessária a partir desse acervo, qual seja a produção de projetos públicos de arquitetura moderna pelos profissionais paulistas.

\section{REFERÊNCIAS}

BRAUND, Yves. Arquitetura contemporânea no Brasil. São Paulo: Perspectiva, 1985.

CESTARO, Lucas R. Lebret e o urbanismo da SAGMACS: o Brasil no foco do Mouvement Économie et Humanisme. Anais: Seminário de história da cidade e do urbanismo, v.11, n.5, 2010. s/p. 
Disponível em: <http://unuhospedagem.com.br/revista/rbeur/index.php/shcu/article/download/1385/1358>.

DAL CO, Francesco. A contemporaneidade do inatual. In: PISANI, Daniele. Paulo Mendes da Rocha. Obra Completa. São Paulo: GG, 2013.

PISANI, Daniele. Paulo Mendes da Rocha: obra completa. São Paulo: GG, 2013.

ROLDAN, Dinalva. Um ideário urbano em desenvolvimento: a experiência de Louis Joseph Lebret em São Paulo de 1947 a 1958. São Paulo: FAU-USP, 2012.

\section{BIBLIOGRAFIA RELATIVA AO PLANO}

ALVES, André A. As implicações historiográficas da consulta às fontes primárias no estudo da arquitetura escolar pública paulista (1959-1962). FÓRUM, v. 4, n. 2, p.24-48, 2011.

ALVES, André A. Arquitetura escolar em São Paulo 1959-1962: o PAGE, o IPESP e os arquitetos modernos paulistas. São Paulo: FAU-USP, 2008.

CIDADE Universitária Armando Salles de Oliveira. America Magazine, São Paulo, n.2, 1962.

ARTIGAS, João Vilanova. Sobre escolas. Acrópole, São Paulo, ano 32, n.377, p. 10-13, set. 1970.

BARROS, José Roberto Mendonça de. A experiência regional de planejamento. In: MINDLIN, Betty (org.) Planejamento no Brasil. São Paulo: Perspectiva, 1974. p. 111-137.

BUZZAR, Miguel (coord.) Difusão da arquitetura moderna no Brasil: o patrimônio arquitetônico criado pelo Plano de Ação do Governo Carvalho Pinto (1959-1963). Relatório do projeto de pesquisa referente ao Edital do convênio Condephaat/ Fapesp, processo - 2011/51108-0. São Paulo, 2015.

CABRAL, Neyde A. Joppert. A Universidade de São Paulo: modelos e projetos. São Paulo: FAU-USP, 2004.

CAMARGO, Mônica Junqueira de. Conexões brutalistas paulistas. In: X Docomomo nacional, Curitiba, 2013.

CAMARGO, Mônica Junqueira de. O setor das humanas como patrimônio arquitetônico e a história da arquitetura paulista. In: LIRA, Jose Tavares Correia de (Org.). Patrimônio construído da USP: preservação, gestão e memória. São Paulo: Edusp, 2014.p. 200-219. (Cadernos CPC, 10)

CORDIDO, Maria Tereza. Arquitetura forense do estado de São Paulo: produção moderna, antecedentes e significados. São Carlos: IAU-USP, 2007.

INSTITUTO DOS ARQUITETOS DO BRASIL. Departamento de São Paulo. Ata da Assembleia Geral realizada no dia 24/02/1959.

INSTITUTO DOS ARQUITETOS DO BRASIL. Departamento de São Paulo. Ata da Assembleia Geral realizada no dia 10/08/1959.

INSTITUTO DOS ARQUITETOS DO BRASIL. Departamento de São Paulo. Ata da Assembleia Geral realizada no dia 20/08/1959.

INSTITUTO DOS ARQUITETOS DO BRASIL. Departamento de São Paulo. Ata da Assembleia Geral realizada no dia 08/09/1959. 
LANG, Ana Beatriz da Silva Gordo. Carvalho Pinto: trajetória e projeto político. São Paulo 1991. Trabalho realizado pelo Centro de Estudos Rurais e Urbanos com bolsa de recém-doutor do CNPQ.

PINTO, Carvalho. Plano de Ação do Governo. São Paulo: Imprensa Oficial, 1959.

Mensagem Apresentada pelo Governador Carvalho Pinto à Assembleia Legislativa do Estado de São Paulo. São Paulo: Imprensa Oficial, 1960.

Mensagem Apresentada pelo Governador Carvalho Pinto à Assembleia Legislativa do Estado de São Paulo - 14 de março de 1961, para a Lei no 6.047, de 27 de janeiro de 1961, São Paulo, Decretos e Relatórios. São Paulo: Imprensa Oficial, [s.d].

Exposição do Governador Carvalho Pinto para a $4^{a}$ Reunião de Governadores com Excelentíssimo Presidente da República. São Paulo: Imprensa Oficial, 1961.

Mensagem Apresentada pelo Governador Carvalho Pinto à Assembleia Legislativa do Estado de São Paulo. São Paulo: Imprensa Oficial, 1962.

2º Plano de Ação, 1963-1962. São Paulo: Imprensa Oficial, 1962. Disponível em: <http:// www.iau.usp.br/pesquisa/grupos/artarqbr/planodeacao/index.php/pesquisa>.

SEGAWA, Hugo. Arquiteturas brasileiras 1900-1990. São Paulo: EDUSP, 1998.

\section{Recebido}

08/03/2016

Aprovado

$16 / 06 / 2016$ 